\title{
EFFECT OF COMMUTATION FAILURES ON TORSIONAL VIBRATIONS OF A TURBINE GENERATOR NEARBY AN HVDC LINK
}

Chi-Hshiung Lin

Department of Electrical Engineering, Kao Yuan University, Kaohsiung County, Taiwan, R.O.C., lin_chi_hshiung@hotmail.com

Follow this and additional works at: https://jmstt.ntou.edu.tw/journal

Part of the Electrical and Computer Engineering Commons

\section{Recommended Citation}

Lin, Chi-Hshiung (2010) "EFFECT OF COMMUTATION FAILURES ON TORSIONAL VIBRATIONS OF A TURBINE GENERATOR NEARBY AN HVDC LINK," Journal of Marine Science and Technology. Vol. 18: Iss. 1, Article 8. DOI: $10.51400 / 2709-6998.1866$

Available at: https://jmstt.ntou.edu.tw/journal/vol18/iss1/8

This Research Article is brought to you for free and open access by Journal of Marine Science and Technology. It has been accepted for inclusion in Journal of Marine Science and Technology by an authorized editor of Journal of Marine Science and Technology. 


\section{EFFECT OF COMMUTATION FAILURES ON TORSIONAL VIBRATIONS OF A TURBINE GENERATOR NEARBY AN HVDC LINK}

\begin{abstract}
Key words: HVDC link, turbine generator, commutation failure, torsional vibration.

ABSTRACT

For an HVDC system, it is studied the torsional vibrations induced on the inverter side turbine generators due to a rectifier side ac faults. It is found there may be up to several times difference in the torsional torques induced at the turbine shafts and blades for the same fault, depending on the inverter commutation behavior. Further, if a single-phase-to-ground fault takes place with the commutation failure, it might cause a more serious impact on the turbine generator unit than a threephase-to-ground fault without commutation failure.
\end{abstract}

Chi-Hshiung Lin*

\section{INTRODUCTION}

Commutation Failure (CF) is a phenomenon that the transfer of current from the off-going valve to the on-going valve is not successful for a thyristor converter. For an HVDC system, it is one of the serious events and a lot of works have been done to understand such a phenomenon $[16,22]$. It is shown that the basic reason for commutation failure is that the extinction angle during system disturbance is too small. When a thyristor valve is going to turn off, the internal excess charges must be removed before it can establish a forward blocking capability. If forward voltage is imposed across the turning-off valve before the storage charges have been removed completely, the thyristor valve cannot turn off successfully. As a result, commutation failure happens. Therefore, it requires a sufficient negative voltage-time area (or a sufficiently large extinction angle) for a valve to ensure the completion of a commutation process.

Also, a lot of works have been done to know the cause and consequence of the commutation failure [7, 18, 19]. It is shown that commutation failure is mainly caused by the ac

Paper submitted 06/06/08; accepted 02/16/09. Author for correspondence: Chi-Hshiung Lin (e-mail: lin_chi_hshiung@hotmail.com).

*Department of Electrical Engineering, Kao Yuan University, Kaohsiung County, Taiwan, R.O.C. network faults. When there are disturbances in the ac systems, a sudden transient reduction in the commutation voltage or a sudden rise in the dc current might be induced. And reports have revealed that commutation failures may happen during an ac system disturbance, where the voltage reduction is only as small as $10 \%$. Once commutation failure happens, it generally causes stresses on valves, delay in restart time and, even, interruption of transmitted power. Fortunately, many approaches have been found to be helpful for alleviating the problem. For examples, larger smoothing reactors may limit the rate of rise of dc current, increasing in short circuit ratio of the inverter bus may reduce the voltage dip during faults, a greater margin angle for an inverter may provide more time for commutation, etc. Moreover, there are control approaches proposed for decreasing the commutation failure frequency [1, $4,14,15,17,20,21]$. They are generally to continuously monitor the ac system disturbances. Occasionally a dangerous situation is detected, the control system advances the firing time of thyristors.

However, commutation failure for an HVDC link is still a problem couldn't be wholly get rid of so far, so it is necessary to investigate its effects. In this paper, we focus on the one for commutation failure to influence the torsional vibrations induced at turbine generator units. For this subject, few literatures have been found. In [5] and [6], the impacts of the inverter station faults on the rectifier side turbine generators and on the inverter side turbine generators were investigated, respectively. These two papers have taken into consideration the commutation failure. In [3], the impacts on rectifier side turbine generators causing by rectifier station faults were investigated. However, the paper didn't involve the commutation failure. According to the survey above, it can be seen that the impacts of rectifier side faults on inverter side turbine generators haven't been studied. So, the studies in the paper would make up the deficiency.

\section{SYSTEM STUDIED}

\section{System Descriptions}

The system studied is an asynchronously linked HVDC system, as shown in Fig. 1. A 1,000 MW (500 kV, 2 kA) dc 


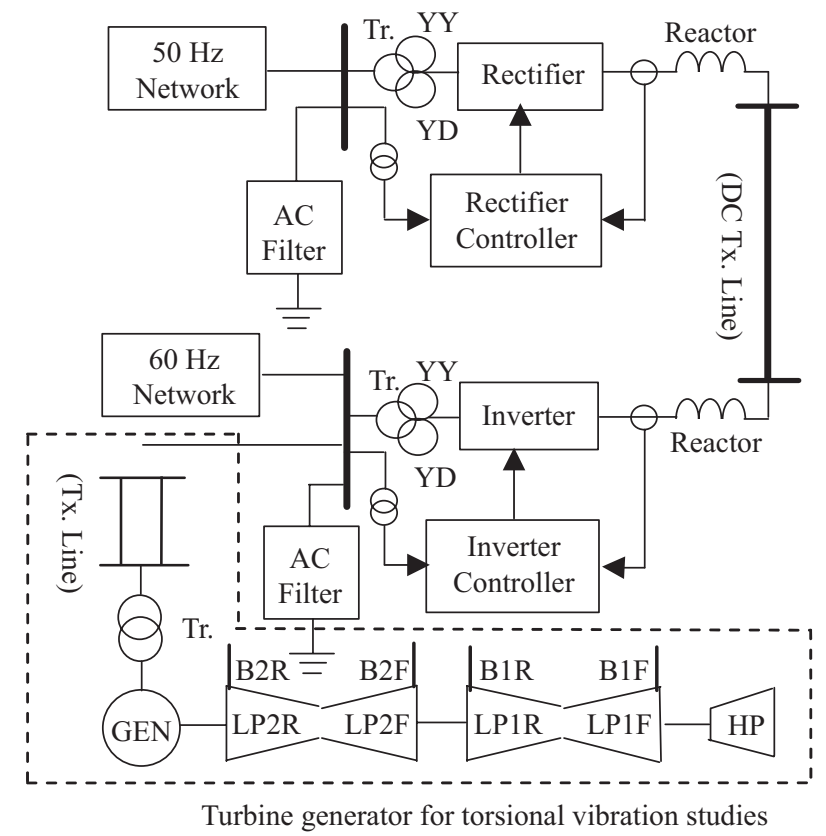

Fig. 1. System studied.

transmission line is used to transmit power from a 10,000 MVA $(345 \mathrm{kV}, 50 \mathrm{~Hz})$ network to a 5,000 MVA $(500 \mathrm{kV}, 60 \mathrm{~Hz})$ network. The converter configuration is typical, including a 12-pulse rectifier and a 12-pulse inverter. The dc transmission line is $300 \mathrm{~km}$ long, with a $0.5 \mathrm{H}$ of smoothing reactor on each side. Each converter transformer, in a typical YY-and-YD winding configuration, equips with a tap changer. In normal operation, the primary voltage of the rectifier transformer is keeping at $0.90 \mathrm{pu}$ and the one of the inverter transformer is keeping at $0.96 \mathrm{pu}$. The reactive power required by the converters is provided by a set of filters (capacitor bank plus $11^{\text {th }}$, $13^{\text {th }}$ and high-pass filters, total 600 MVAR on each side).

\section{System Modeling}

A Matlab/Simulink/Power-System-Blockset program, which is used for academic studies by Hydro-Quebec [2], is adopted for the transient simulations. Some modifications were made to fit it for the studies, of course. The program scheme and details of system modeling can be found in the previous works [8-11].

For the general components, the packaged models are used if available, to which we don't give un-necessary details. The $\mathrm{dc}$ transmission line is modeled as a $\pi$ circuit model for considering the capacitive effects. The rectifier and inverter units are composed of thyristors, and an individual thyristor is modeled as a switch in series with a resistor, an inductor and a voltage drop. The switch will be turn on/turn off (according to the preset switching characteristics) depending on the firing pulse as well as the thyristor voltage and current. The switching dynamics (e.g. commutation failure) of a converter could be accurately represented by using such a model.
Table 1. Parameters of the converter control model.

\begin{tabular}{|c|c|}
\hline Rectifier control & Inverter control \\
\hline$I_{d c-r e f}=1 \mathrm{pu}$ & $I_{d c-\text { ref }}=1 \mathrm{pu}$ \\
\hline$V_{d c-\text { ref }}=2 \mathrm{pu}$ & $V_{d c-\text { ref }}=1 \mathrm{pu}$ \\
\hline$\alpha_{\max }=165 \mathrm{deg}$ & $\alpha_{\max }=165 \mathrm{deg}$ \\
\hline$\alpha_{\min }=5 \mathrm{deg}$ & $\alpha_{\min }=92 \mathrm{deg}$ \\
\hline$I_{d c-\text { marg }}=0.0 \mathrm{pu}$ & $I_{d c-\text { marg }}=0.1 \mathrm{pu}$ \\
\hline$V_{d c-\text { marg }}=0.0 \mathrm{pu}$ & $V_{d c-\text { marg }}=0.05 \mathrm{pu}$ \\
\hline Current regulator & Voltage regulator \\
\hline$k_{p}=45 \mathrm{deg} / \mathrm{pu}$ & $k_{p}=35 \mathrm{deg} / \mathrm{pu}$ \\
\hline$k_{i}=4500 \mathrm{deg} / \mathrm{pu} / \mathrm{sec}$ & $k_{i}=2250 \mathrm{deg} / \mathrm{pu} / \mathrm{sec}$ \\
\hline \multicolumn{2}{|c|}{ Measuring time constant } \\
\hline \multicolumn{2}{|c|}{$T_{C}=0.0003 \mathrm{sec}$} \\
\hline \multicolumn{2}{|c|}{$T_{V}=0.01 \mathrm{sec}$} \\
\hline \multicolumn{2}{|c|}{$T_{F}=0.0001 \mathrm{sec}$} \\
\hline
\end{tabular}

Particularly emphasized here are the HVDC link controls. The control strategy of the HVDC link studied is the Constant Current and Constant Voltage (CC\&CV) scheme. Both the rectifier and inverter have the same control structure, except that the voltage control would not be activated for the rectifier. A detailed converter control model is adopted, of which the schematic diagram is shown in Fig. 2, with the parameters listing in Table 1. The controller has a voltage and a current regulator operating in parallel. All the regulators are typical PI controllers. Four control modes are available for the converters: (1) current control; (2) voltage control; (3) alpha minimum limitation; (4) alpha maximum limitation.

For the master control of a rectifier, the current order is first determined, with constrains being imposed to keep the current within the maximum and minimum limits. The maximum current is determined by the Voltage Dependent Current Order Limiter (VDCOL) that is implemented for helping to recover from faults. The VDCOL automatically reduce the reference current set point when dc line voltage decreases (e.g. during a severe ac fault). The PI type of current regulator accounts for current regulating. If the current regulator doesn't hit any limits, the rectifier is operating in the current control mode. In case it hits the low limit the rectifier turns to operate in the alpha minimum limitation mode.

For the master control of an inverter, the action is reversed. Normally, the inverter operates in the voltage control mode with a PI controller to regulate the voltage. It will switch to the current control mode when the rectifier regulator touch the low limit and unable to maintain the desired dc current.

\section{APPROACHES OF TRIGGERING A COMMUTATION FAILURE}

It is well known that during a network fault at rectifier side the rectifier is expected to remain at its minimum firing angle, and therefore for the most part the only active controller 


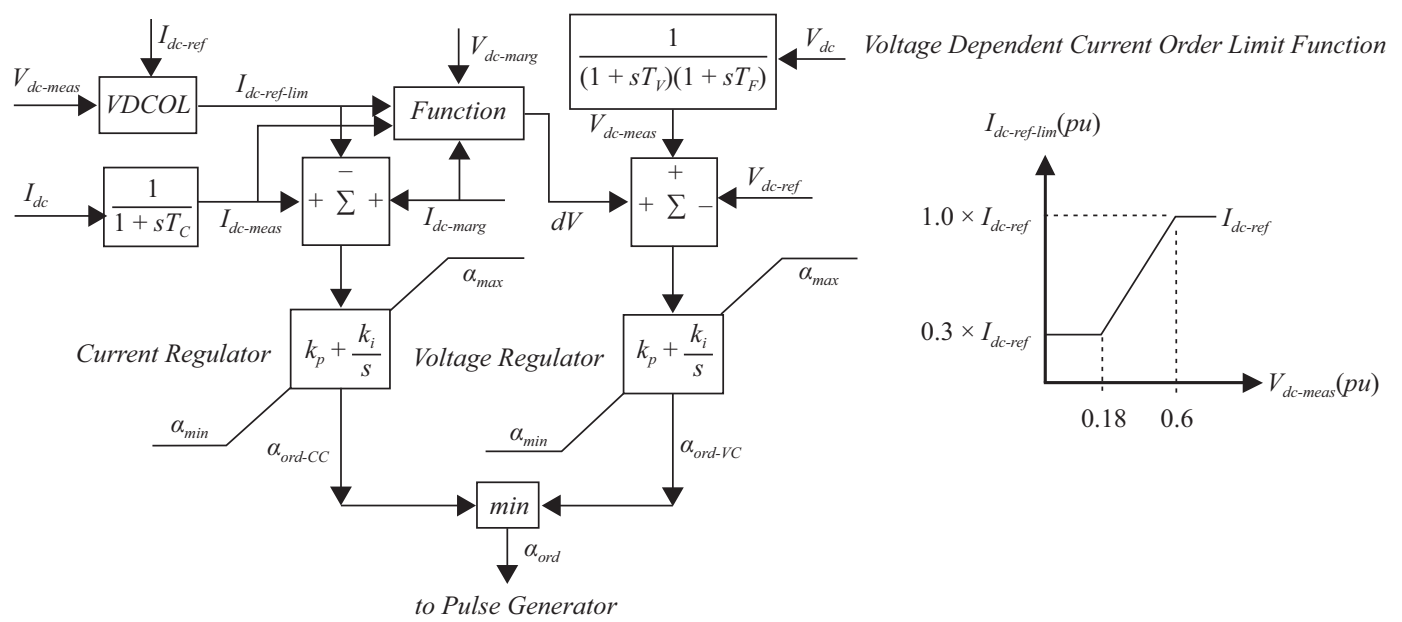

Fig. 2. Schematic diagram of the converter control model.

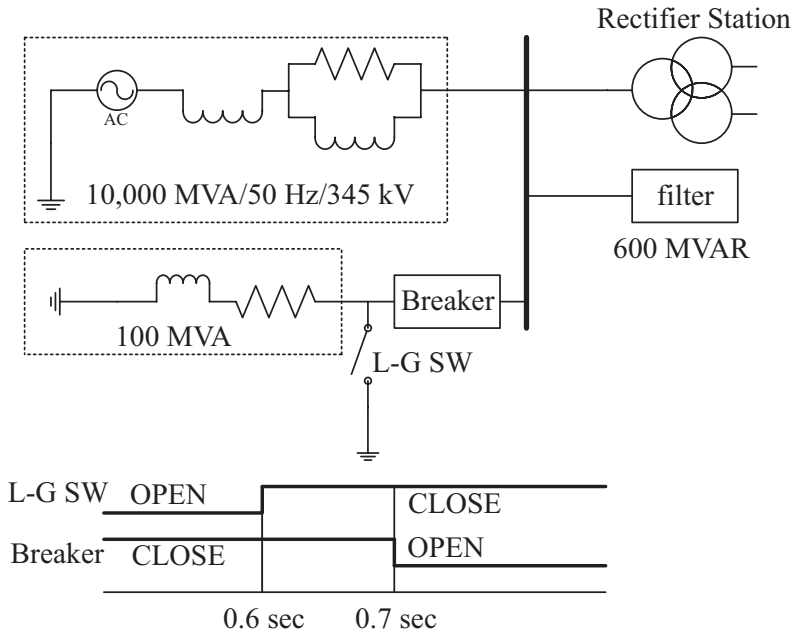

Fig. 3. Circuit switching scheme for simulating the faulting and clearing operations.

should be the inverter current controller. Thus, the parameters of this controller are important to the inverter commutation behavior.

For inducing a commutation failure, time is a crucial factor. Too fast response may make the negative voltage-time area required by an inverter valve become in-sufficient for commutation to complete. So just increasing the setting values of the proportional constant $(\mathrm{kp})$ and/or the integral constant $(\mathrm{ki})$ may trigger the commutation failure.

Depending on the success or failure of commutation, the HVDC link will present wholly different performance in responding to the fault. We shall examine this for a threephase-to-ground (3p-g) fault case without commutation failure phenomenon and a single-phase-to-ground (1p-g) fault case with commutation failure phenomenon.

\section{Faulting and Clearing Simulations}

The circuit switching scheme for simulating the faulting

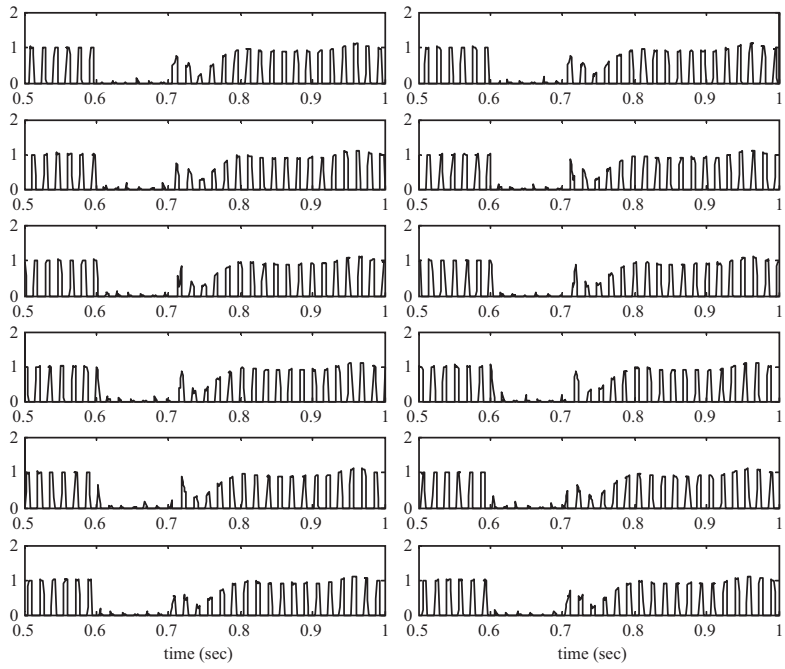

Fig. 4. Inverter valves pu currents (in sequence of 1 to 6 from top to bottom) for the 3p-g fault without CF (left: YY side, right: YD side).

and clearing operations at rectifier ac side network is shown in Fig. 3. A normally open switch (L-G SW) is forced to close at $0.6 \mathrm{~s}$ to account for a grounding fault occurring at the 100 MVA feeder. A normally closed circuit breaker trips at $0.7 \mathrm{~s}$ to clear the fault.

\section{3p-g Fault Case without Commutation Failure}

For the nominal inverter current controller setting of $(\mathrm{kp}$, $k i)=(45 \mathrm{deg} / \mathrm{pu}, 4500 \mathrm{deg} / \mathrm{pu} / \mathrm{sec})$, transient simulations have been made to ensure the well operations of the HVDC link under the situations of load changing and reference changing, and the link can also recover successfully in a temporary dc or ac line fault.

For subjecting to a $3 \mathrm{p}-\mathrm{g}$ fault, the responses are briefing as the following. The currents flow through the twelve inverter valves are shown in Fig. 4. It can be seen that neither the YY 

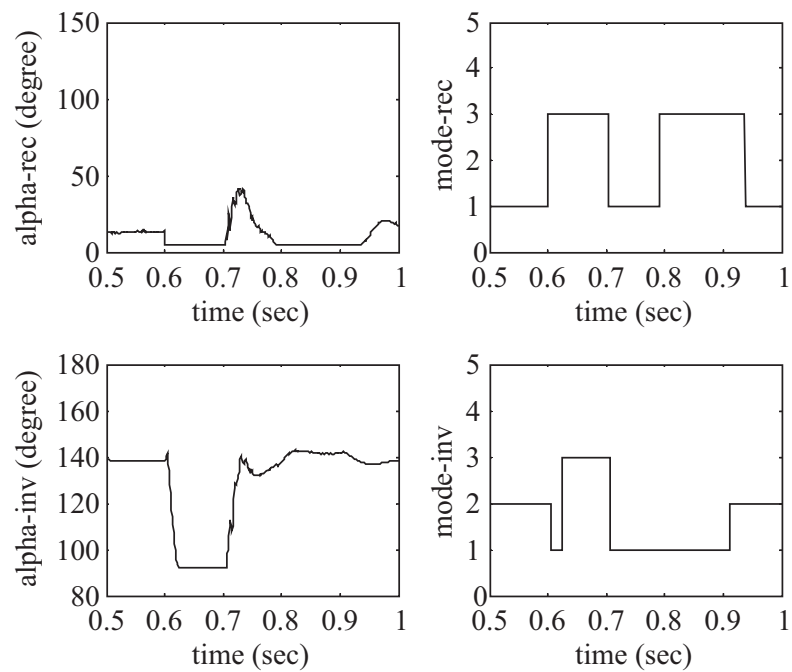

Fig. 5. Firing angles and operation modes of converters for the $3 p$-g fault without CF.
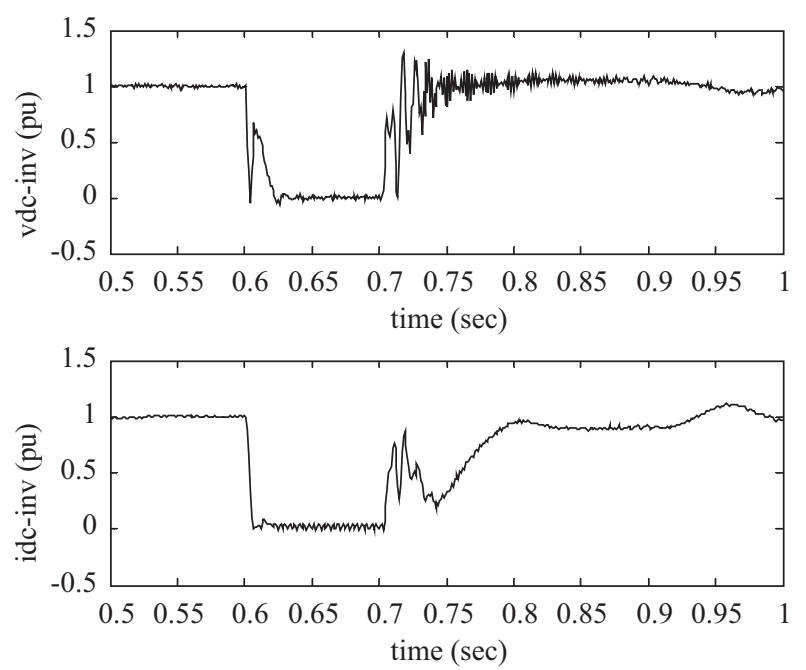

Fig. 6. Inverter side de voltage and current for the 3p-g fault without CF.

side nor the YD side valves occur the commutation failure. In Fig. 5, the firing angle and operation mode of the rectifier and inverter are shown. In the steady state, the rectifier is operated in the current control mode, and the inverter in the voltage control mode. The firing angles are about 20 degrees and 140 degrees, respectively, for the rectifier and inverter. When the fault is applied, the operation mode of the rectifier (mode-rec) changes to the alpha minimum limitation, with the firing angle (alpha-rec) falling down to 5 degrees. And the inverter is in charge of the control operation in the fault period. When the fault is cleared, both the rectifier and inverter govern the control action, and coordinate each other. It can be seen that there is no conflict between the rectifier and inverter during fault, clear and recovery periods. So there is not any especially abnormal behavior taking place in the inverter side dc link voltage (vdc-inv) and current (idc-inv), which are shown in Fig. 6.

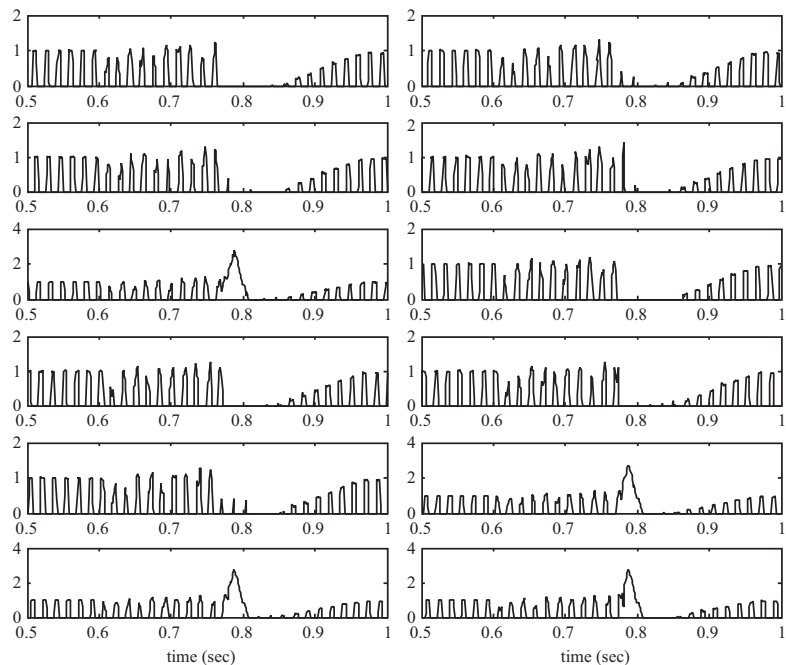

Fig. 7. Inverter valves currents (in sequence of 1 to 6 from top to bottom) for the 1p-g fault with CF (left: YY side, right: YD side).
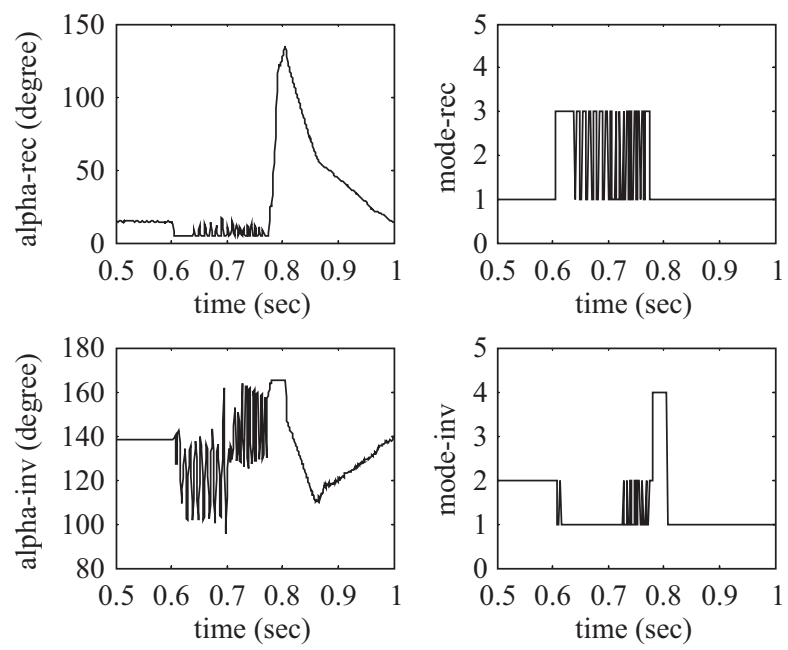

Fig. 8. Firing angles and operation modes of converters for the 1p-g fault with CF.

\section{1p-g Fault Case with Commutation Failure}

By changing the inverter current control parameter to $(\mathrm{kp}$, $k i)=(145 \mathrm{deg} / \mathrm{pu}, 4500 \mathrm{deg} / \mathrm{pu} / \mathrm{sec})$, the responses subjecting to a $1 \mathrm{p}-\mathrm{g}$ fault are observed again. The currents flow through the twelve inverter valves are shown in Fig. 7. It can be seen that, at $0.77 \mathrm{~s}$ or so, a commutation failure occurs in the valves 3 and 6 of YY side, and in the valves 5 and 6 of YD side.

The firing angle and operation mode for the rectifier and inverter are shown in Fig. 8. It is important to see that the control action is disturbed by the commutation failure, leading to the abnormal functioning of HVDC link. During the recovery period, the rectifier is pushed to the inverter operation (with the firing angle changing to about 140 degrees), and the inverter to the alpha maximum limitation mode (with the firing angle changing to 165 degrees). So the power transfer of HVDC link is interrupted due to the commutation failure 

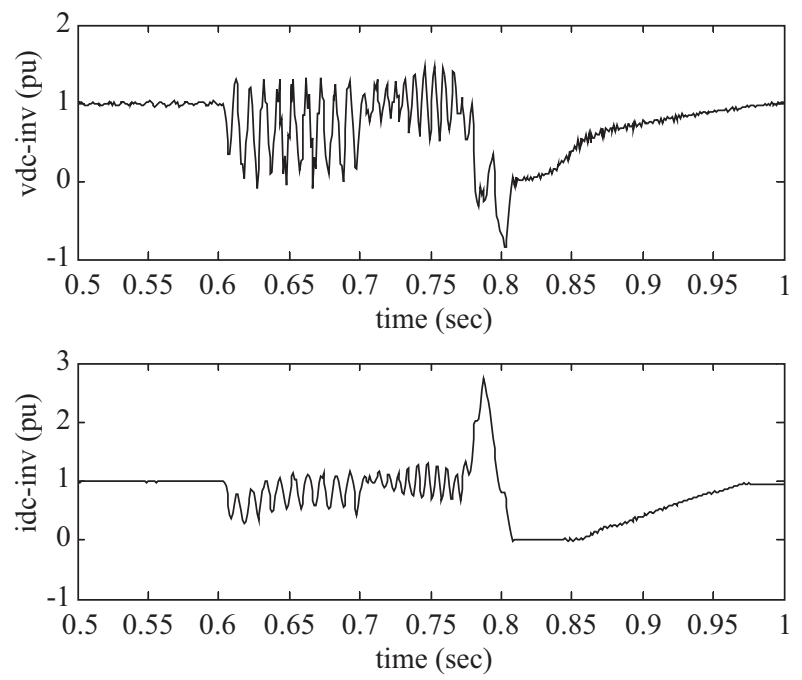

Fig. 9. Inverter side de voltage and current for the $1 \mathrm{p}$-g fault with $\mathrm{CF}$.

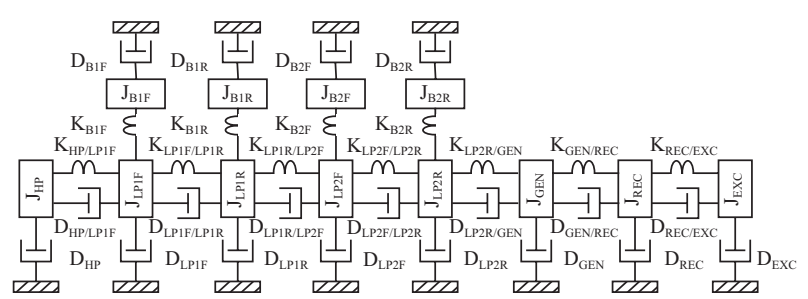

Fig. 10. Mass-damping-spring model of the turbine-generator-exciterblade mechanism.

and needs to be re-established, as can be observed from Fig. 9. This phenomenon causes an excess impact on the system.

\section{TORSIONAL VIBRATIONS}

To study the effect of a commutation failure on the torsional vibrations induced at the shafts and blades of a turbine generator nearby the HVDC link, a $950 \mathrm{MW}$ turbine generator unit is included in the $60 \mathrm{~Hz}$ network. The generator is a 4-pole/1800 rpm machine with voltage rating of $23.75 \mathrm{kV}$, which is driven by a steam turbine unit and supplies power to the converter bus via a step-up transformer (with power rating of $1057 \mathrm{MVA}$ ) and two parallel transmission lines. The steam turbine unit, including a high-pressure stage (HP) and two low-pressure stages (LP1, LP2) steam turbines, is a closecoupled and cross-compound reheat unit that operates at a rotational speed of $1800 \mathrm{rpm}$. Each low-pressure turbine has $\mathrm{F}$ and $\mathrm{R}$ spindles, including eleven rows of blades with twisting structure and serrated type of root.

\section{Generator Model}

The turbine generator sub-system is also constructed by the Matlab/Simulink/Power-System-Blockset packaged models. For the generator, it is a six-order state-space d-q- 0 model and an IEEE type-1 AVR regulates the generator terminal voltage.
Table 2. Parameters of the Turbine-generator-exciter-blade Model.

\begin{tabular}{lccc}
\hline $\begin{array}{l}\text { Rotor } \\
\text { section }\end{array}$ & $\begin{array}{c}\text { Torque } \\
\text { distribution }(\%)\end{array}$ & $\begin{array}{c}\text { Inertia constant } \\
\text { (MW-s/MVA) }\end{array}$ & $\begin{array}{c}\text { Damping coefficient } \\
\text { (MW-s/MVA-rad) }\end{array}$ \\
\hline HP & 31 & 0.1787 & 0.00180 \\
LP1F & 14.45 & 0.6462 & 0.00023 \\
LP1R & 14.45 & 0.6410 & 0.00021 \\
LP2F & 14.45 & 0.6499 & 0.00021 \\
LP2R & 14.45 & 0.6602 & 0.00021 \\
GEN & 0.0 & 1.1616 & 0.00012 \\
REC & 0.0 & 0.00344 & 0.00000 \\
EXC & 0.0 & 0.00236 & 0.00000 \\
B1F & 2.8 & 0.0344 & 0.00004 \\
B1R & 2.8 & 0.0344 & 0.00004 \\
B2F & 2.8 & 0.0344 & 0.00004 \\
B2R & 2.8 & 0.0344 & 0.00004 \\
\hline
\end{tabular}

Table 2. continued.

\begin{tabular}{lc}
\hline Shaft section & $\begin{array}{c}\text { Stiffness coefficient } \\
\text { (MW/MVA-rad) }\end{array}$ \\
\hline HP/LP1F & 144.15 \\
LP1F/LP1R & 1595.0 \\
LP1R/LP2F & 206.0 \\
LP2FLP2R & 1584.9 \\
LP2R/GEN & 325.28 \\
GEN/REC & 117.16 \\
REC/EXC & 1.61 \\
LP1F/B1F & 36.2 \\
LP1R/B1R & 36.2 \\
LP2F/B2F & 36.2 \\
LP2R/B2R & 36.2 \\
\hline
\end{tabular}

\section{Turbine Generator Mechanical Model}

It is very difficult to characterize a complex turbine generator mechanical structure, yet it has been commonly accepted to use the lumped mass-damping-spring model for the studies on torsional vibrations. In Fig. 10, it is shown such a model for the turbine-generator-exciter-blade mechanism studied, with parameters listing in Table 2. One could refer to [12] for details of how the model and its parameters were derived.

According to the lumped mass-damping-spring model, dynamic equations of motion can be derived. Here, we use a very particular approach, electromechanical analogy [13], to derive them. For an individual section (e.g. Rotor-j section) as shown in the left part of Fig. 11, it can be transformed into an equivalent circuit as in the right part of Fig. 11. By the loop analyses, one could find easily the state space equations as the followings.

LOOP 1 equations:

$$
\frac{d}{d t} \phi_{j}=\omega_{j}
$$




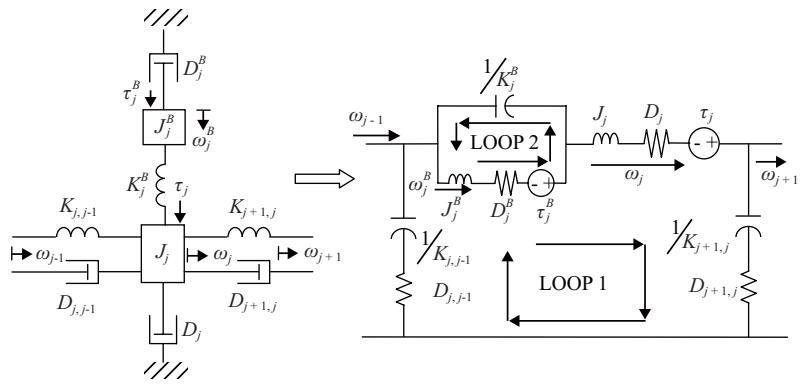

Fig. 11. Rotor-j section of the mass-damping-spring model and its equivalent circuit.

Table 3. Eigen-values of the Turbine-generator-exciter-blade Model.

\begin{tabular}{cc}
\hline Eigen-values & Frequency $(\mathrm{Hz})$ \\
\hline$-1.95620262425+/-1806.76898690731 \mathrm{i}$ & 287.55 \\
$-0.04277156682+/-719.08407897187 \mathrm{i}$ & 114.44 \\
$-0.03615391816+/-698.19047239941 \mathrm{i}$ & 111.12 \\
-0.06628545682 & - \\
$-0.06272706389+/-122.00368899893 \mathrm{i}$ & 19.42 \\
$-0.07436986263+/-232.13115405894 \mathrm{i}$ & 36.94 \\
$-1.33455883572+/-252.58777166885 \mathrm{i}$ & 40.20 \\
$-0.36759195240+/-289.60578342518 \mathrm{i}$ & 46.09 \\
$-0.08216900537+/-333.30197487371 \mathrm{i}$ & 53.05 \\
$-0.06376719130+/-326.51259771547 \mathrm{i}$ & 51.96 \\
$-0.05532705174+/-312.89871647952 \mathrm{i}$ & 49.80 \\
$-0.05653688675+/-313.05339760415 \mathrm{i}$ & 49.82 \\
\hline
\end{tabular}

$$
\begin{aligned}
\frac{d}{d t} \omega_{j}= & \left\{\tau_{j}-\left(D_{j}+D_{j, j-1}+D_{j+1, j}\right) \omega_{j}+D_{j, j-1} * \omega_{j-1}\right. \\
& +D_{j+1, j} * \omega_{j+1}-\left(K_{j, j-1}+K_{j+1, j}+K_{j}^{B}\right) \varphi_{j} \\
& \left.+K_{j, j-1} * \varphi_{j-1}+K_{j+1, j} * \varphi_{j+1}+K_{j}^{B} * \varphi_{j}^{B}\right\} / J_{j}
\end{aligned}
$$

LOOP 2 equations:

$$
\begin{gathered}
\frac{d}{d t} \phi_{j}^{B}=\omega_{j}^{B} \\
\frac{d}{d t} \omega_{j}^{B}=\left(\tau_{j}^{B}+K_{j}^{B} * \phi_{j}-K_{j}^{B} * \phi_{j}^{B}-D_{j}^{B} * \omega_{j}^{B}\right) / J_{j}^{B}
\end{gathered}
$$

where $J, K, D$ represent respectively the inertia, stiffness and damping of rotor or of shaft. The $\phi$ and $\omega$ are angular displacement and angular velocity respectively. For turbine rotors, $\tau$ is the torque delivered by the turbine. The torque is determined by the opening of the main control valves and reheater/intercepter valves that is dependent on turbine governor action. For the generator rotor, $\tau$ is the electromagnetic torque delivered to power system. As to the ones with superscript " $B$ ", they are the blade variables or parameters.
Table 4. $\Delta \mathrm{T}$ (pu) for various cases.

\begin{tabular}{|c|c|c|c|}
\hline Case & 1p-g w/o CF & 1p-g w/ CF & 3p-g w/o CF \\
\hline LP2R/GEN & 0.42 & 1.2 & 0.8 \\
\hline B2F & 0.017 & 0.09 & 0.03 \\
\hline
\end{tabular}
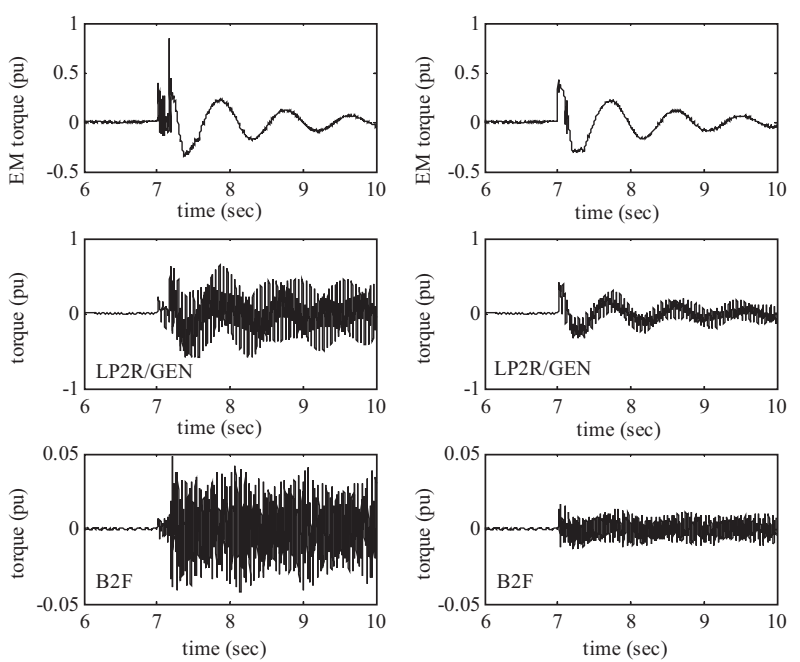

Fig. 12. Turbine generator responses (left: under the 1p-g fault with CF, right: under the 3p-g fault without $\mathrm{CF}$ ).

By rewriting the torque equations to the power equations and further transforming the equations into the Matlab/Simulink model, the turbine-generator-exciter-blade model can thus be incorporate with the electric power system.

By making an eigen-analysis on the turbine-generator-exciterblade model, the eigen-values can be obtained as in Table 3, which reveals the natural frequencies of the mechanism.

\section{Transient Responses}

The transient simulations for both the $3 \mathrm{p}-\mathrm{g}$ and $1 \mathrm{p}$-g faults with and without $\mathrm{CF}$ have been made. However, just the responses for the 3p-g fault case without CF and the 1p-g fault case with $\mathrm{CF}$ are demonstrated here. The simulations are under the assumption that the ground faults were taken place in the rectifier side ac network at $7 \mathrm{sec}$, lasting for 5 cycles, and then were cleared automatically. Converter blocking capability is not included in the simulations.

In Fig. 12, it is shown the turbine generator responses for the two cases, including the generator electromagnetic torque (EM torque) as well as the torsional torques at theLP2R/GEN shaft and B2F blade sections. It can be seen that there is an additional EM torque disturbance due to the commutation failure during the recovery period for the $1 \mathrm{p}-\mathrm{g}$ fault case. And this causes excess torsional vibrations to be induced in both the shafts and blades as can be seen in the figure.

For understanding easily, we tabulate the maximum-tominimum values of torsional torque $(\Delta \mathrm{T})$ in Table 4 . The columns 2 and 3 are to compare the $\Delta \mathrm{T}$ between conditions with and without $\mathrm{CF}$ for the $1 \mathrm{p}$-g fault. It can be found that 


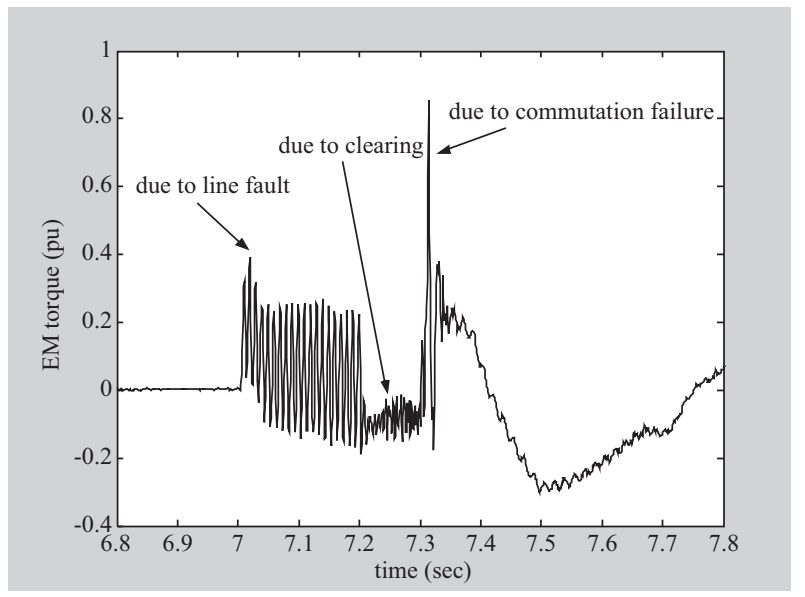

Fig. 13. EM torque disturbances.

there is a remarkable difference in $\Delta \mathrm{T}$ induced for the two conditions. For the shaft, there is a three-time difference. For the blade, there is a six-time difference. The columns 3 and 4 are to compare the $\Delta \mathrm{T}$ between the $1 \mathrm{p}$-g fault with $\mathrm{CF}$ and the $3 p-g$ fault without CF. It is significant to find that a single-phase-to-ground fault causes a more serious impact on the turbine mechanism than a three-phase-to-ground fault does. Thus, it can be known that the commutation failure is so significant to affect the stressing of turbine shafts and blades.

\section{Effects of Clearing Time}

In many literatures, it has been shown that torsional vibrations are functions of clearing time. For the situations studied, it is shown that clearing time is no longer a significant factor. The reason is obvious because the EM torque disturbances due to faulting and clearing are far smaller than the one due to commutation failure, just as demonstrated in Fig. 13. However, clearing time will indirectly affect the commutation failure timing, so the generator EM torque and torsional vibrations induced at turbine shafts and blades will be affected as well. In Fig. 14, it is shown the $\Delta \mathrm{T}$, as a function of clearing time (in cycles), for EM torque, LP2R/GEN shaft torque and $\mathrm{B} 2 \mathrm{~F}$ blade torque, respectively. It can be seen that clearing time is influential, but the influence is relatively small.

\section{CONCLUSIONS}

The commutation failure in an HVDC link is a very complicated phenomenon. It is not likely to wholly prevent an HVDC link from such an event. So it is necessary to carefully analyze its effects. For the system studied, it is summarized below the findings about the torsional vibrations induced on an inverter side turbine generator due to a rectifier side ac fault.

1. For the same fault, there may be up to several times of difference in torsional torques induced at the shaft and blade sections, depending on if a commutation failure happened or not.
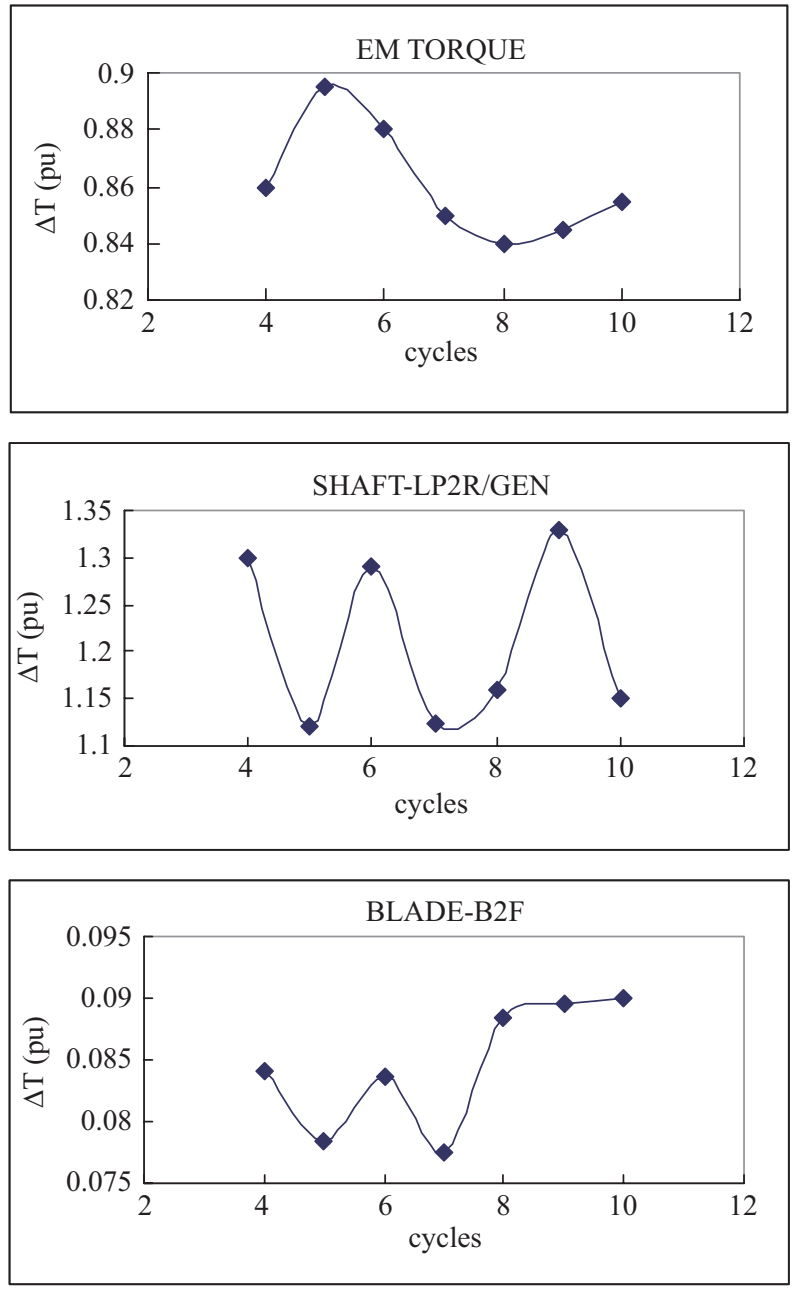

Fig. 14. $\Delta \mathrm{T}$ for different clearing time.

2. If a single-phase-to-ground fault takes place with commutation failure, it might cause a more serious impact on a turbine generator than a three-phase-to-ground fault without commutation failure.

\section{REFERENCES}

1. Bauman, J. and Kazerani, M., "Commutation failure reduction in HVDC systems using adaptive fuzzy logic controller," IEEE Transactions on Power Systems, Vol. 22, No. 4, pp. 1995-2002 (2007).

2. Casoria, S., "Power system blockset for use with simulink," HydroQuebec, TEQSIM International Inc (1998).

3. Faried, S. O. and El-Serafi, A. M., "Effect of HVDC converter station faults on turbine-generator shaft torsional torques," IEEE Transactions on Power Systems, Vol. 12, No. 2, pp. 875-881 (1997).

4. Hansen, A. and Havemann, H., "Decreasing the commutation failure frequency in HVDC transmission systems," IEEE Transactions on Power Delivery, Vol. 15, No. 3, pp. 1022-1026 (2000).

5. Iravani, M. R., Zhao, Z., and Hamouda, R. M., "Impact of inverter station on torsional dynamics of parallel HVDC-AC power system," IEEE Transactions on Power Systems, Vol. 8, No. 3, pp. 997-1003 (1993).

6. Kim, C. K., Yang, B. M., Ahn, Y. H., and Choi, J. G., "Impact of generator of inverter station on torsional dynamics of HVDC system," IEEE 2002 
28th Annual Conference of the Industrial Electronics Society, No. 1, pp. 538-543 (2002).

7. Kristmundsson, G. M. and Carroll, D. P., "The effect of AC system frequency spectrum on commutation failure in HVDC inverters," IEEE Transactions on Power Delivery, Vol. 5, No. 2, pp. 1121-1128 (1990).

8. Lin, C. H., "Phenomena caused by a misfire fault in an HVDC converter valve and the impact on a turbine generator," Journal of Technology, Vol. 23, No. 2, pp. 23-30 (2008).

9. Lin, C. H., "Impact of fire-through and misfire in rectifier valves on a turbine generator neighboring to a HVDC inverter station," Journal of Marine Science and Technology, Vol. 16, No. 4, pp. 241-248 (2008).

10. Lin, C. H., "Frequency limitations for disposing natural torsional modes of a large scale turbine generator in an asynchronous HVDC system," International Journal of Electrical Engineering, Vol. 14, No. 1, pp. 51-64 (2007).

11. Lin, C. H., "The effect of converter configurations of HVDC links on suband super-synchronous disturbances to turbine units," Electric Power Systems Research, Vol. 74, pp. 427-433 (2005).

12. Lin, C. H., "The effects of a MOV surge arrester on blade vibrations of a large scale turbine unit," Electric Power Components and Systems, Vol. 31, No. 8, pp. 757-776 (2003).

13. Lin, C. H., "Restricting turbine blade fatigue based on electromechanicalanalogy circuit analysis," International Journal of Power and Energy Systems, Vol. 22, No. 3, pp. 150-158 (2002).

14. Lin, L., Zhang, Y., Zhong, Q., and Wen, F., "Identification of commutation failures in HVDC systems based on wavelet transform," ISAP 2007 International Conference on Intelligent Systems Applications to Power Systems, pp. 1-5 (2007).
15. Machida, T. and Yoshida, Y., "A method to detect the deionization margin angle and to prevent the commutation failure of an inverter for DC transmission," IEEE Transactions on Power Apparatus and Systems, Vol. 86, No. 3, pp. 259-262 (1967)

16. Rahimi, E., Gole, A. M., Davies, J. B., Fernando, I. T., and Kent, K. L., "Commutation failure in single- and multi-infeed HVDC systems," The 8th IEE International Conference on AC and DC Power Transmission, pp. 182-186 (2006).

17. Sun, Y. Z., Peng, L., Ma, F., Li, G. J., and Lv, P. F., "Design a fuzzy controller to minimize the effect of HVDC commutation failure on power system," IEEE Transactions on Power Systems, Vol. 23, No. 1, pp. 100-107 (2008).

18. Tamai, S., Naitoh, H., Ishiguro, F., Sato, M., Yamaji, K., and Honjo, N., "Fast and predictive HVDC extinction angle control," IEEE Transactions on Power Systems, Vol. 12, No. 3, pp. 1268-1275 (1997).

19. Thio, C. V., Davies, J. B., and Kent, K. L., "Commutation failures in HVDC transmission systems," IEEE Transactions on Power Delivery, Vol. 11, No. 2, pp. 946-957 (1995).

20. Tian, H. Y. and Sng, E. K. K., "A novel solution to restore a three-phase thyristor inverter from commutation failure due to voltage dip," PESC 2004 IEEE 35th Annual Power Electronics Specialists Conference, No. 2, pp. 906-912 (2004).

21. Zhang, L. and Dofnas, L., "A novel method to mitigate commutation failure in HVDC systems," International Conference on Power System Technology, No. 1, pp. 51-56 (2002).

22. Zou, G., Zheng, J., and Chen, X., "Study on commutation failure in an HVDC inverter," International Conference on Power System Technology, No. 1, pp. 503-506 (1998). 